\title{
PELAKSANAAN MANAGEMENT PROCEDURE PENGELOLAAN SUMBERDAYA IKAN BERKELANJUTAN DI INDONESIA
}

\author{
Chomariyah \\ Fakultas Hukum Universitas Hang Tuah Surabaya \\ Jl.Arif rahman Hakim, Keputih, Sukolilo, Kota Surabaya \\ Email: chomariah@hangtuah.ac.id
}

\begin{abstract}
At the eighteenth annual meeting of the CCSBT agreed on the use of Management Procedure (MP) as a guide to total allowable catches globally against Southern Bluefin Tuna. It aims to ensure that the biomass of fish stocks can reach the target redevelopment of up to 20\%. CCSBT set the allowable catch based on the results of the MP. MP aims to maintain the stability of the fishing industry reduces the possibility of the number of catches in the future to decrease. Three-year period total allowable catches globally is; 2014 is 12449 tons, year 2015-2017 is 14647 tons and 17647 tons Year 2018-2020 be included ndonesia. Implementation Management Procedure by Indonesia is a resource management strategy that allows the fish formally to ensure that the fish resources can be utilized in a sustainable manner.
\end{abstract}

Keywords: Management Procedure, Fish Resources, Sustainable

\begin{abstract}
Abstrak
Pada pertemuan tahunan CCSBT kedelapan belas telah disepakati mengenai penggunaan Management Procedure (MP) sebagai panduan jumlah tangkapan yang diperbolehkan secara global terhadap Tuna Sirip Biru Selatan. Hal ini bertujuan untuk memastikan bahwa biomassa stok ikan dapat mencapai target pembangunan kembali hingga 20\%. CCSBT menetapkan jumlah tangkapan yang diperbolehkan berdasarkan hasil dari MP. MP bertujuan untuk menjaga stabilitas industri perikanan mengurangi kemungkinan jumlah tangkapan di masa yang akan datang menjadi menurun. Periode tiga tahun jumlah tangkapan yang diperbolehkan secara global adalah; tahun 2014 adalah 12.449 ton, Tahun 2015-2017 adalah 14.647 ton dan Tahun 2018-2020 menjadi 17.647 ton termasuk ndonesia. Pelaksanaan Management Procedure oleh Indonesia merupakan strategi pengelolaan sumberdaya ikan secara formal yang memungkinkan untuk menjamin agar sumberdaya ikan tersebut dapat dimanfaatkan secara berkelanjutan.
\end{abstract}

\section{Kata kunci: Manajemen Pengelolaan, Sumberdaya Ikan, Berkelanjutan.}

\section{A. PENDAHULUAN}

Sumberdaya ikan (selanjutnya disebut SDI) di laut lepas merupakan salah satu sumber pangan dan komoditi industri kelautan yang sangat penting di dunia. Menurut laporan Food and Agriculture Organizations (selanjutnya disebut FAO) dalam The State of World Fisheries and Aquaculture (selanjutnya disebut SOFIA) tahun 2012 menyebutkan, bahwa sektor perikanan mendukung mata pencaharian sekitar 540 juta penduduk dunia dan produksi 
perikanan dunia mencapai 128 juta ton ikan. ${ }^{1}$ Lebih lanjut SOFIA 2012 menyebutkan, bahwa persediaan ikan dunia mengalami penurunan akibat eksploitasi berlebih (over-exploited), yaitu: $85 \%$ SDI dunia dalam keadaan over-exploited dan fully exploited serta berada dalam batas tangkapan maksimum lestari. ${ }^{2}$ Laporan SOFIA tersebut menjelaskan dua kondisi yang perlu mendapat perhatian yaitu penangkapan ikan mendorong perkembangan perekonomian industri kelautan, dan kondisi penangkapan ikan berlebih yang menimbulkan tekanan pada SDI terutama di laut lepas.

Penangkapan berlebih (overfishing) terhadap SDI sebenarnya telah terjadi sejak akhir tahun 1970-an, jumlah kapal penangkap ikan jarak jauh (distant-water fishing vessels) ${ }^{3}$ yang beroperasi di laut lepas mengalami peningkatan dan keberadaan mereka mengancam kapalkapal serta ketersediaan ikan di negara pantai yang berdekatan dengan laut lepas. ${ }^{4}$

Apabila kondisi overfishing di laut lepas terjadi terus menerus dan tidak dikendalikan maka akan mengancam reproduksi beberapa jenis ikan di negara pantai. Hal ini terjadi karena ikan memiliki sifat ketergantungan antara yang satu dengan lainnya sebagai satu kesatuan rantai makanan (food chain). Apabila satu jenis ikan terancam reproduksinya dan mengalami penurunan ketersediaan (depletion) maka akan berpengaruh terhadap ketersediaan jenis ikan lainnya.

Penyebab overfishing ada dua, yaitu pemahaman yang keliru terhadap prinsip "Freedom of the high seas" dan perkembangan teknologi armada perikanan dan alat penangkap ikan. Pertama, pemahaman yang keliru terhadap prinsip "Freedom of the high seas" adalah ketika laut diartikan sebagai "Res nullius" sehingga penangkapan ikan dilakukan secara tidak terkendali dan tanpa batas. Prinsip kebebasan di laut lepas, termasuk kebebasan menangkap ikan (freedom of fishing), seharusnya dipahami sebagai "Res communis omnium"6 yang berarti laut adalah hak bersama seluruh umat, maka negara-negara memiliki hak yang sama dalam memanfaatkan SDI di laut lepas.

Penyebab overfishing yang kedua adalah perkembangan teknologi armada kapal perikanan dan alat penangkapan ikan berskala besar yang cenderung membahayakan keberlanjutan sumberdaya ikan. Mukadimah UNGA Res. 44/225 tahun 1989 juga menyebutkan bahwa terdapat lebih dari seribu armada kapal perikanan yang menggunakan

1 FAO, The State of World Fisheries and Aquaculture (SOFIA), 2012, lihat www.fao.org/ icatalog/inter-e.htm, diakses tanggal 12 Oktober 2012.

2 Batas tangkapan maksimum lestari adalah kondisi tingkat pemanfaatan sumberdaya ikan tidak melebihi batasan yang ditetapkan sehingga persediaannya tetap berkelanjutan.

3 Distant-water fishing vessel adalah kapal penangkap ikan yang melakukan kegiatan penangkapan di luar wilayah kawasan pantai negara asalnya dan mampu berlayar jauh hingga ke laut lepas. Kapal penangkap ikan jenis ini sekaligus berfungsi untuk tempat pengalengan ikan dan langsung diproses untuk komoditi ekspor ke negara lain. Philippe Sands, Principles of International Environmental Law, second edition, Cambridge University Press, United Kingdom, 2003, hlm. 569.

4 RR. Churchill dan AV. Lowe, The Law of the Sea, third edition, Manchester University Press, United Kingdom, 1999, hlm.299.

5 Pemikiran laut sebagai res nullius, menurut pemikiran ini laut merupakan daerah yang tidak ada pemiliknya (terra nullius), karena itu merupakan daerah yang Vacuum Juris sehingga siapapun dapat menguasainya, dapat memilikinya. Mochtar Kusumaadmaja, Hukum Laut Internasional, cet. IX, Binacipta, Bandung, 1999, hlm. 3-4.

6 Pemikiran res communis omnium, menurut pemikiran ini laut lepas merupakan wilayah terbuka bagi setiap orang, yang berarti milik umum, sama sekali tidak dapat dimiliki oleh siapapun, ibid. 
teknologi large-scale pelagic driftnet di Samudera Pasifik, Atlantik, dan Samudera Hindia serta di wilayah laut lepas lainnya, dan telah mengakibatkan over-exploitation sumberdaya hayati (living marine resources) di laut lepas. ${ }^{7}$

Beberapa praktik penangkapan ikan yang tergolong illegal dan menimbulkan overfishing antara lain, armada kapal perikanan yang sengaja masuk wilayah perairan zona ekonomi eksklusif suatu negara tanpa izin dan menangkap ikan secara berlebih. Cara lainnya adalah armada kapal perikanan yang telah mendapatkan izin secara legal namun melakukan tindakan illegal dengan cara berpindah dari wilayah penangkapan ikan yang sudah ditetapkan (pelanggaran fishing ground), dengan cara menggunakan alat penangkapan yang dilarang (bahan kimia, bahan biologis, dan bahan peledak). Praktik-praktik penangkapan ikan tersebut dapat mengganggu dan merusak keberlanjutan SDI, sehingga membuat langkah-langkah pengelolaan dan konservasi menjadi tidak efektif.

Laporan IUCN tahun 2016, dalam Critically Endangered Red List Category \& Criteria $I U C N,{ }^{8}$ menyatakan bahwa terdapat lima spesies tuna terancam punah, yaitu tuna sirip biru selatan (Thunnus maccoyii) sangat terancam punah; tuna sirip biru Atlantik (Thunnus thynnus) terancam; tuna mata besar (Thunnus obesus) rentan; tuna sirip kuning (Thunnus albacares) dan tuna albacore (Thunnus alalunga) hampir terancam. ${ }^{9}$ Dari laporan tersebut terlihat bahwa kondisi tuna sirip biru selatan sangat terancam punah, sehingga perlu mendapat perhatian dan kerjasama masyarakat internasional untuk menjaga ketersediaannya agar tetap dapat dimanfaatkan secara berkelanjutan.

Adanya tekanan yang terus menerus atas SDI dan kecenderungan penurunan hasil tangkapan menjadi salah satu fokus permasalahan dalam United Nations Conference on Straddling Fish Stocks and Highly Migratory Fish Stocks. Menurut UNCLOS 1982 pengelolaan SDI di perairan negara pantai adalah tanggung jawab negara pantai sedangkan pengelolaan SDI di laut lepas merupakan tanggung jawab bersama dari negara-negara. Dengan demikian harus ada komitmen yang kuat dari negara pantai, negara penangkap ikan jarak jauh, dan kewajiban negara bendera untuk melakukan pengawasan terhadap warganegaranya yang menangkap ikan di laut lepas berdasarkan standar hukum internasional.

Komitmen ini dilaksanakan melalui kerjasama internasional, yaitu pembentukan Regional Fisheries Management Organizations (selanjutnya disebut RFMOs) atau organisasi pengelolaan perikanan regional. RFMOs memiliki tujuan yang sama, yaitu melakukan pengelolaan dan konservasi sumberdaya ikan bermigrasi terbatas dan bermigrasi jauh. Organisasi yang mengelola sumberdaya ikan jenis bermigrasi jauh di laut lepas telah banyak

7 UNGA, A/RES/44/225, 22 Desember 1989, mukadimah paragraf 5 dan 10.

8 The IUCN Red List of Threatened Species (IUCN Red List) merupakan dokumen yang berisi tentang daftar status konservasi berbagai jenis makhluk hidup seperti hewan dan tumbuh-tumbuhan yang dikeluarkan oleh IUCN. Daftar ini dikeluarkan pertama kali pada tahun 1948 dan merupakan panduan paling berpengaruh mengenai status keanekaragaman hayati. IUCN Red List menetapkan kriteria untuk mengevaluasi status kelangkaan suatu spesies. Lihat <http://www.iucnred list.org/about/red-list-overview\#introduction> diakses tanggal 28 Februari 2016.

9 The IUCN Red List of Threatened Species, 2012, lihat <www.iucnredlist.org/technical-documents/categories-andcriteria> diakses tanggal 12 September 2012. 
didirikan salah satunya adalah Commission for the Conservation of Southern Bluefin Tuna (selanjutnya disebut CCSBT) atau Komisi Konservasi Tuna Sirip Biru Selatan.

Dari uraian di atas maka permasalahan yang akan dibahas dalam penelitian ini adalah; bagaiamana pelaksanaan management procedure pengelolaan sumberdaya ikan berkelanjutan di Indonesia.

\section{B. PEMBAHASAN}

CCSBT adalah sebuah organisasi antar pemerintah yang bertanggung jawab atas pengelolaan dan konservasi ikan tuna sirip biru selatan secara global dan termasuk distribusinya. Tujuan CCSBT adalah untuk memastikan, melalui pengelolaan yang tepat, konservasi dan pemanfaatan yang optimal terhadap tuna sirip biru selatan. ${ }^{10}$ Anggota Komisi adalah Australia, Jepang, Selandia Baru, Korea Selatan, Badan Perikanan Taiwan (Fishing Entity of Taiwan), Indonesia dan Cooperating Non-Members terdiri dari Filipina, Afrika Selatan dan Uni Eropa.

Southern Bluefin Tuna (Thunnus maccoyii) atau tuna sirip biru selatan merupakan jenis ikan pelagis besar dan termasuk dalam kategori ikan bermigrasi jauh (Highly Migratory Species). Alat penangkapan ikan yang sering digunakan untuk menangkap ikan jenis bermigrasi jauh adalah alat tangkap jenis long-line (rawai tuna), ${ }^{11}$ dan purse seine. $^{12}$

CCSBT dalam menetapkan TAC dan alokasi diantara Negara-negara anggota didasarkan pada pertimbangan sebagai berikut: ${ }^{13}$

1. Bukti ilmiah yang berhubungan dengan jumlah tangkapan;

2. Kebutuhan pembangunan perikanan tuna sirip biru selatan yang berkelanjutan dan teratur;

3. Kepentingan-kepentingan Negara anggota yang ZEE-nya dilalui oleh migrasinya tuna sirip biru selatan;

4. Kepentingan-kepentingan Negara anggota yang kapalnya melakukan penangkapan tuna sirip biru selatan termasuk mereka yang secara historis melakukan penangkapan dan mereka yang perikanan tuna sirip biru selatannya belum berkembang;

5. Kontribusi setiap Negara anggota untuk konservasi dan penelitian ilmiah.

Beberapa resolusi yang telah dihasilkan CCSBT terkait dengan pengelolaan dan konservasi tuna sirip biru selatan, yang bersifat mengikat, antara lain:

1. Resolution on establishing the CCSBT Vessel Monitoring System; ${ }^{14}$

10 Pasal 3 CCSBT 1993.

11 Tuna longline merupakan alat tangkap yang terdiri dari rangkaian sejumlah pancing yang dioperasikan sekaligus. Satu kapal tuna longline biasanya mengeoperasikan 1000-2000 mata pancing untuk sekali operasi. Alat tangkap ini termasuk alat tangkap yang ramah lingkungan karena bersifat selektif terhadap jenis ikan yang ditangkap.Direktur Sumberdaya Ikan Direktorat Jenderal Perikanan Tangkap, "Permasalahan dan tantangan yang dihadapi Indonesia terkait dengan Keanggotaan dalam Organisasi Perikanan Regional", Workshop Pelaksanaan UNIA 1995 di Indonesia, Kementerian Kelautan dan Perikanan, Denpasar, Bali, 2010, hlm.2.

12 Purse seine atau pukat cincin, merupakan alat tangkap yang dilengkapi dengan tali cincin. Fungsi tali cincin untuk menjaring ikan pada saat akhir penangkapan, Ibid.

13 Pasal 8 ayat (4) CCSBT 1993. 
2. Resolution on the Implementation of a CCSBT Catch Documentation Scheme; ${ }^{15}$

3. Resolution on Establishing a Program for Transhipment by Large-Scale Fishing Vessels; 16

4. Resolution on the Establishment of Record of Authorised Farms, ${ }^{17}$

5. Resolution on amendment of the Resolution on "Illegal, Unregulated and Unreported Fishing (IUU) and Establishment of a CCSBT Record of Vessels over 24 meter Authorized to Fish for Southern Blufin Tuna"; ${ }^{18}$

6. Resolution on the Total Allowable Catch and Future Mangement of Southern Bluefin Tuna; ${ }^{19}$

7. Resolution on Action Plans to Ensure Compliance with Conservation and Management Measures; ${ }^{20}$

8. Resolution on the Adoption of a Management Procedure; ${ }^{21}$

9. Resolution on the Allocation of Global Total Allowable Catch; ${ }^{22}$

10. Resolution on Limited Carry-forward of Unfished Annual TAC of Southern Bluefin Tuna within Three Year Quota Bloks, ${ }^{23}$

Resolusi tentang establishing the CCSBT Vessel Monitoring System (selanjutnya disebut VMS) adalah suatu kesepakatan untuk mengembangkan dan mengimplementasikan sistem pemantauan kapal yang dimulai pada resolusi VMS pada tahun 2006. Pertimbangan yang mendasari resolusi ini adalah pentingnya sistem pemantauan kapal sebagai bagian integral dari Monitoring, Control and Surveillance (selanjutnya disebut MCS) yang efektif untuk tuna sirip biru selatan, khususnya untuk memastikan keberlanjutan jangka panjang dari stok. VMS merupakan salah satu bagian terpenting dalam langkah-langkah MCS untuk mencegah IUU Fishing, hal ini diidentifikasi dalam "the Course of Actions diterima dalam Kobe Joint Meeting of Tuna Regional Fisheries Management Organisations. Pada pertemuan tersebut disepakati perlunya untuk menetapkan standar minimum untuk VMS.

Langkah-langkah dalam menetapkan TAC dan langkah-langkah lainnya yang telah ditetapkan berdasarkan Pasal 8 ayat (3) CCSBT wajib mengikat Negara-negara anggotanya. ${ }^{24}$

Ketentuan tentang Scientific Committee, diatur dalam Pasal 9 CCSBT 1993, yang mempunyai kewajiban untuk:

1. Mengkaji dan menganalisis status dan kecenderungan-kecederungan populasi tuna sirip biru selatan;

2. Mengkoordinasikan penelitian dan pengkajian tuna sirip biru selatan;

14 Resolusi diterima pada Pertemuan Tahunan ke-15, 14-17 Oktober 2008, di Auckland, New Zealand.

15 Ibid.

16 Ibid.

17 Ibid.

18 Ibid. Resolution on IUU Fishing and Establishment of a CCSBT Record Vessels, diterima pada pertemuan tahunan ke-10 tahun 2003.

19 Resolusi diterima pada Pertemuan Tahunan ke-16, 20-23 Oktober 2009, Jeju Island, Korea Selatan.

${ }_{20}$ Ibid.

21 Resolusi diterima pada Pertemuan Tahunan ke-18, 10-13 Oktober 2011, Bali, Indonesia

22 Ibid.

23 Ibid

24 Pasal 8 ayat (7) CCSBT 1993. 
3. Melaporkan kepada Komisi penemuan-penemuan termasuk konsensus, pandanganpandangan mayoritas dan minoritas terhadap status persediaan tuna sirip biru selatan;

4. Membuat rekomendasi-rekomendasi, kepada Komisi melalui konsensus terhadap hal-hal mengenai pengelolaan, konservasi dan pemanfaatan optimal tuna sirip biru selatan; dan

5. Mempertimbangkan hal-hal lain yang dirujuk oleh Komisi.

CCSBT melaksanakan strategi pengelolaan yang disebut sebagai Management Procedure. Resolusi tentang pelaksanaan Management Procedure atau disebut juga sebagai Bali Procedure diterima pada pertemuan tahunan ke-18 tahun 2011, berisi tentang strategi pembangunan kembali tuna sirip biru selatan secara formal sehingga memungkinkan SDI tersebut pulih kembali ke tingkat yang berkelanjutan. Strategi pembangunan kembali yang terdapat dalam Management Procedure memberikan pedoman tentang batas tangkapan global dan menyediakan industri perikanan agar menangkap ikan secara periode waktu yang telah tersedia. CCSBT berkomitmen untuk memulihkan persediaan tuna sirip biru selatan dengan menetapkan target reference points sesuai UNFSA 1995, sementara sebesar $20 \%$ dari tingkat unfished pada tahun 2035. ${ }^{25}$ Dalam mengadopsi Management Procedure, CCSBT menekankan perlunya untuk meningkatkan kemungkinan pembangunan kembali persediaan tuna sirip biru selatan.

Pengelolaan terhadap TAC global dikendalikan dalam tiga periode waktu untuk mengurangi kemungkinan penurunan TAC di masa depan. Management Procedure untuk menentukan TAC global periode tahun 2015-2017. ${ }^{26}$

Tabel 1.

TAC untuk masing-masing anggota CCSBT

\begin{tabular}{|c|c|c|c|}
\hline Negara & $\mathbf{2 0 1 5}$ & $\mathbf{2 0 1 6 - 2 0 1 7}$ & $\mathbf{2 0 1 8 - 2 0 2 0}$ \\
\hline Japan & 4,847 & 4,737 & $6,117^{* 1}$ \\
\hline Australia & 5,665 & 5,665 & 6,165 \\
\hline Republic of Korea & 1,140 & 1,140 & $1,240.5$ \\
\hline Fishing Entity of Taiwan & 1,140 & 1,140 & $1,240.5$ \\
\hline New Zealand & 1,000 & 1,000 & 1,088 \\
\hline Indonesia & 750 & 750 & $1,023^{* 1}$ \\
\hline South Africa & 40 & 150 & $450^{* 1}$ \\
\hline European Union & 10 & 10 & 11 \\
\hline
\end{tabular}

Keterangan

*1 (These figures reflect the voluntary transfers of 21t that Japan is providing to Indonesia and 27t that Japan is providing to South Africa for the 2018 to 2020 quota block. The starting point for Japan, Indonesia and South Africa in considering the allocation from 2021 will be 6165t, 1002t, and 423t respectively.)

Parameter Management Procedure adalah (1) untuk membangun kembali status stok menuju target reference point sebesar $20 \%$ dari original spawning biomass pad tahun 2035; (2) ditetapkan kemungkinan $70 \%$ untuk mencapai sasaran pembangunan kembali sementara; (3) minimum kenaikan atau penurunan TAC sebesar 100 ton; (4) maksimum kenaikan atau penurunan sebesar 3000 ton; (5) TAC ditetapkan untuk periode tiga tahun berdasarkan

${ }^{25}$ Lihat <http://www.ccsbt.org/userfiles/file/docs_english/operational_resolution/Resolution_Management_Procedure.pdf〉, diakses tanggal 14 April 2013

${ }^{26}$ Lihat <http://www.ccsbt.org/site/total_allowable_catch. php>., diakses tanggal 14 April 2013. 
resolusi tentang TAC global, tahun 2010-2011 sebesar 9.449 ton; tahun 2012 sebesar 10.449 ton; tahun 2013 sebesar 10.949 ton dan tahun 2014 sebesar 12,449 ton.

Langkah-langkah Indonesia terkait dengan pelaksanaan Management Procedure antara lain melalui mengambil langkah-langkah untuk mencegah atau mengurangi kegiatan penangkapan ikan berlebih dan penangkapan ikan yang melebihi kapasitas dan menjamin bahwa tingkat usaha penangkapan ikan tidak melebihi tingkat yang sepadan dengan pemanfaatan sumberdaya ikan yang lestari. Hal ini tercermin dalam kebijakan beerapa peraturan yaitu :

1. Undang-Undang No 31 tahun 2004 sebagaimana telah diubah dengan Undang Undang No. 45 Tahun 2009 tentang Perikanan

2. PP No. 60 Tahun 2007 tentang konservasi sumberdaya ikan, telah ditetapkan beberapa Peraturan Menteri antara lain:

a. Peraturan Menteri Kelautan dan Perikanan Nomor PER. 03/MEN/2010 Tentang Tata Cara Penetapan Status Perlindungan Jenis Ikan, yang merupakan peraturan pelaksanaan dari Pasal 24 ayat (2).

b. Peraturan Menteri Kelautan dan Perikanan Nomor PER. 04/MEN/2010 Tentang Tata Cara Pemanfaatan Jenis ikan dan Genetik ikan,

c. Peraturan Menteri Kelautan dan Perikanan Nomor PER. 03/MEN/2009 tentang Penangkapan Ikan dan /atau Pengangkutan Ikan di Laut Lepas, yang kemudian dicabut dan diganti dengan Peraturan Menteri Kelautan dan Perikanan Nomor PER. 12/MEN/2012 tentang Usaha Perikanan Tangkap di Laut Lepas.

Berdasarkan uraian diatas maka langkah-langkah yang sudah ditetapkan dalam beberapa peraturan seharusnya ditindaklanjuti dan dilaksanakan sehingga dapat terjaga ketersediaan sumberdaya ikan secara berkelajutan.

\section{PENUTUP}

Pelaksanaan Management Procedure oleh Indonesia merupakan strategi pengelolaan sumberdaya ikan tuna sirip biru selatan secara formal sehingga memungkinkan sumberdaya ikan tersebut pulih kembali dan dapat dimanfaatkan secara berkelanjutan. Strategi pembangunan kembali yang terdapat dalam Management Procedure memberikan pedoman bagi pengelolaan industri perikanan nasional agar menangkap ikan sesuai dengan periode waktu yang ditetapkan. Langkah-langkah Indonesia terkait dengan pelaksanaan Management Procedure antara lain melalui mengambil langkah-langkah untuk mencegah atau mengurangi kegiatan penangkapan ikan berlebih dan penangkapan ikan yang melebihi kapasitas dan menjamin bahwa tingkat usaha penangkapan ikan tidak melebihi tingkat yang sepadan dengan pemanfaatan sumberdaya ikan yang lestari. Langkah tersebut secra yuridis dituangkan dalam beberapa produk hukum, mulai dari Undang-Undang, PP hingga Peraturan Menteri. 


\section{DAFTAR PUSTAKA}

\section{Buku}

Ariadno, Melda Kamil, Hukum Internasional Hukum Yang Hidup, Diadit Media, Jakarta, 2007

, Indonesian Responsibility for High Seas Fisheries, A Legal Analysis, Lambert Academic Publishing, Germany, 2012

Attard, David Joseph, The Exclusive Economic Zone in International Law, Clarendon Press, Oxford, 1987

Campbell, Enid, Legal Research, The Law Book Company, Melbourne, 1996

Churchill, R. R., and A. V. Lowe, The Law of the Sea, Manchester University Press, Manchester UK, 1999

Crawford, James and Donald R. Rothwell, The Law of the Sea in the Asia Pacific Region, Martinus Nijhoff Publishers, Netherlands, 1995

Departemen Luar Negeri, United Nations Convention on the Law of the Sea 1982, Pusat Studi Hukum Internasional dan Perjanjian Internasional, Jakarta, 2000

Diantha, I Made Pasek, ZEE Indonesia berdasarkan Konvensi Hukum Laut PBB 1982, Mandar Maju, Jakarta, 2002

FAO, M. Boutet, Note on Some Legal Aspect of the Precautionary Approach to Fishery Technology, FAO Fisheries Technical paper, 350,

FAO, Precautionary Approach ti Fisheries, Scientific Papers, FAO Fisheries Technical Paper, 350/2

Gullett, Warwick, Fisheries Law in Australia, Lexis Nexis, Butterworths, Australia, 2008 , "The threshold test of the Precautionary Principle in Australian Court and Tribunals: Lessons for Judicial Review," Environmental and Planning Law Journal, 1997

,Christopeher Paterson, Elizabeth fisher, Substantive Precautionary decision-making: the Australian fisheries management authority's lawful pursuit of the precautionary principle, Faculty of Law Papers, University of Wollongong Research Online, Australia, 2001

Kusumaatmadja, Mochtar, Hukum Laut Internasional, Bina Cipta, Bandung, 1986 , Perlindungan dan Pelestarian Lingkungan Laut, Dilihat dari Sudut Hukum Internasional, Regional dan Nasional, Sina Grafika dan Pusat Studi Wawasan Nusantara, 1992 , Bunga Rampai Hukum Laut, Bina Cipta, Bandung, 2001 , Pengantar Hukum Internasional, Alumni, Bandung, 2003 
Kwiatkowska, Barbara, The 200 Mile Exclusive Economic Zone in the New Law of the Sea, Martinus Nijhoff Publishers, London, 1989 Kaye, Stuart B. , International Fisheries Management, Kluwer Law International, The Hague, 2001

Kaczorowska, Alina, Public International Law, Routledge, 2010

\section{Internet}

FAO Fisheries and Aquaculture Technical Paper 457, Review of the State of World Marine Fishery Resources (Rome, 2005), diakses dari <www.fao.org/docrep/fao/009> dan <www.fao.org/fishery/legalframework>, diakses tanggal 29 Mei 2016

FAO Fisheries and Aquaculture Technical Paper 536, International Management of Tuna Fisheries, Arrangement, Challenges and a Way Forward, (Rome, FAO, 2010), diakses dari website FAO www.fao.org/docrep/fao

Marr, Simon, The Southren Bluefin Tuna Cases: The Precautionary Approach and Conservation and Management of Fish Resources, diunduh dari $<h t t p ; / / w w w . z a o e r v . d e>$

Roben, Volker, The Southern Bluefin Tuna Cases: Re-Regionalization of the Settlement of Law of the Sea Dispute?, diunduh dari <http;//www.zaoerv.de>

Sydney, Are K., "Regional Fisheries Organisations and International Fisheries Governance," dalam S.A. Ebbin et al. (eds), A Sea Change: The Exclusive Economic Zone and Governance Institutions for Living Marine Resources, Springer, Netherlands, 2005, ebook diunduh dari <http://www.springerlink.com/ economic/environmental/bool/978$1-4020-3132-8>$.

Website CCSBT, www.ccsbt.org/docs/management_SBT. 